\title{
How Substitutable Is Natural Capital ${ }^{1}$
}

\author{
Anil Markandya \\ FEEM, The World Bank and University of Bath \\ Suzette Pedroso-Galinato \\ The World Bank
}

World Bank Policy Research Working Paper 3803, December 2005

The Policy Research Working Paper Series disseminates the findings of work in progress to encourage the exchange of ideas about development issues. An objective of the series is to get the findings out quickly, even if the presentations are less than fully polished. The papers carry the names of the authors and should be cited accordingly. The findings, interpretations, and conclusions expressed in this paper are entirely those of the authors. They do not necessarily represent the view of the World Bank, its Executive Directors, or the countries they represent. Policy Research Working Papers are available online at http://econ.worldbank.org.

\footnotetext{
${ }^{1}$ This paper is drawn from a larger study on the 'Where is the Wealth of Nations?' (World Bank, 2005a). We wish to thank Giovanni Ruta, Kirk Hamilton, Giles Atkinson and a number of others who have provided useful comments on earlier drafts.
} 


\begin{abstract}
One of the recurring themes in the sustainability literature has been the legitimacy of using an economic framework to account for natural resources. This paper examines the potential for substituting between different inputs in the generation of income, where the inputs include natural resources such as land and energy resources. A nested constant elasticity of substitution (CES) production function is used to allow flexibility in the estimated elasticities of substitution. Also, with this specification, natural resources and other inputs are combined in different levels of the function, thus allowing for different levels of substitutability. Institutional and economic indicators are also incorporated in the production function estimated. Results show that the elasticities derived from functions involving land resources were generally around one or greater, implying a fairly high degree of substitutability. Furthermore, changes in trade openness and private sector investment have a statistically significant and direct relationship with income generation. No statistically significant relationship between income and any of the institutional indicators was found.
\end{abstract}




\section{Background}

One of the recurring themes in the sustainability literature has been the legitimacy of using an economic framework to account for natural resources. Those critical of such an approach contend that wealth accounting assumes natural resource assets can be substituted by produced assets, such as human and physical capital, on a dollar for dollar basis. This, they argue, does not capture the limited degree to which such substitution is possible. A loss of some natural capital, such as an entire ecosystem, surely cannot be made up with an increase in physical capital if the very basis of social existence and well-being are destroyed in the areas affected by that system. This makes them skeptical of the kind of wealth accounts we are constructing here.

While we cannot hope to disentangle the full set of issues embedded in this line of reasoning, we can at least start by focusing on the degree of substitutability between the different assets. Underlying any wealth accounts is an implicit 'production function' which is a blueprint of the combinations of different assets with which we can achieve a given level of output. These blueprints are usually written as a mathematical function, which describes the precise relationship between the availability of different amounts of 'inputs', such as physical and human capital services, and the maximum output they could produce. The substitutability between inputs is then measured as an 'elasticity of substitution'. In general terms, this captures the ease with which a decline in one input can be compensated by an increase in another, while holding output constant. More precisely, it measures how much the ratio of two inputs (e.g. physical capital and land) changes when their relative price changes (e.g. the price of land goes up relative to the price of capital $)^{2}$. The greater the elasticity, the easier it is to make up for the loss of one resource by using another. Generally, an elasticity of less than one indicates limited substitution possibilities.

A commonly used production function, which implies elasticities of one between the inputs, is the 'Cobb-Douglas' form, written as:

$$
Y_{t}=A_{t} K^{\alpha} L^{\beta}
$$

Income or output (Y) is expressed as a function of the levels of capital input (K), labor input (L), an exogenous technological factor (A) and the parameters $\alpha$ and $\beta$, which give the returns to capital and labor respectively. If the national production options could be captured by such a function, with natural capital services included, it would have considerable implications for sustainability. First, it would imply a degree of substitutability between natural and produced capital that would give some comfort to those who argue we can lose some natural capital without seriously compromising our well-being. Related to that it would validate the 'Hartwick Rule', which states that when exploiting natural resources you should ensure you save an amount equal to the rent from those resources if you are to sustain the highest possible level of consumption (Hamilton, 1995). This so-called 'Hartwick Rule' is a useful sustainability policy since it is open to monitoring - we can check whether or not it has been adhered to.

\footnotetext{
${ }^{2}$ Where prices are not defined, we measure the change in the ratio of the inputs resulting from a change in the marginal rate at which one factor can be substituted for another (Chiang, 1984). The discussion is complicated by the fact that there are other definitions of substitution in the literature. We discuss this further below.
} 
Economists have devoted a considerable amount of effort to estimating these elasticities, for inputs such as capital, labor and energy but not natural resources. Although, starting in the 1970s, there were theoretical studies that modeled neoclassical economic growth with nonproduced capital such as natural resources as factors in production (e.g., Stiglitz, 1974a,b; Mitra, $1978)^{3}$; the empirical estimation of the underlying production functions was never carried out, largely because of a lack of data.

This paper is a preliminary attempt in that direction. It is part of a larger study undertaken by the Bank on the Wealth of Nations (World Bank, 2005a). In that study, a database of new wealth estimates has been developed which includes both produced and non-produced capital renewable and non-renewable resources, and human resources. This allows us to estimate a production function that includes the services from these different resources as inputs. This paper examines therefore the economic relationship between total wealth and income generation and takes advantage of the new wealth estimates to estimate a production function based on a larger set of assets. Section II briefly discusses the definitions of elasticities and describes related studies on substitution between different inputs, including natural resources. Section III presents the estimation of the production function and Section IV concludes.

\section{Definitions of elasticities and results of earlier studies}

The definition of an elasticity of substitution given at the beginning of this paper applies unambiguously when there are only two inputs. With more than two inputs, however, the generalization depends on what is assumed constant when the changes in the inputs of interest are being calculated. The issues are familiar to economists - a summary can be found in Kang and Brown (1981). Based on work by Morishima, they define a 'full elasticity of substitution between inputs 'i' and 'j' as $F_{i j}$ where:

$$
F_{i j}=\left|\frac{d \ln \left(X_{i} / X_{j}\right)}{d \ln \left(f_{j} / f_{i}\right)}\right|_{\substack{\left.Y_{\left(f_{k}\right. \text { sonst. }}, f_{i}\right) \text { const. } \\ k \neq i, j}}
$$

$X_{i}$ and $X_{j}$ are levels on inputs ' $\mathrm{i}$ ' and ' $\mathrm{j}$ ' respectively. They are two of the ' $\mathrm{n}$ ' inputs that go into producing output $\mathrm{Y}$, as represented by the production function:

$$
Y=f\left(X_{1}, X_{2} \ldots X_{n}\right)
$$

and

$$
f_{i}=\partial Y / \partial X_{i}
$$

\footnotetext{
${ }^{3}$ A bibliographical compilation of studies can be found in Wagner (2004). One exception to the observation that there is little empirical work is Berndt and Field (1981), who did look at limited natural resource substitution between capital, labor, energy and materials. The studies generally found low elasticities between capital and materials. They did not, however, look at land as an input in the way we do here. Nor did they work with national level data.
} 
Unfortunately, not all studies report this full elasticity of substitution (Equation 2), which corresponds more closely to the concept of substitutability that we are interested in. More commonly the 'Allen' partial elasticity is reported, which, for inputs ' $\mathrm{i}$ ' and ' $\mathrm{j}$ ' is given by $A_{i j}$ :

$$
A_{i j}=\frac{1}{s_{j}} \cdot \frac{\partial \ln X_{i}}{\partial \ln p_{j}}
$$

where $s_{j}$ is the share of total cost of production represented by input ' $\mathrm{j}$ ' and $p_{j}$ is the price of input $j$. Readers will recognize $A_{i j}$ as the weighted cross price elasticity of demand for input 'i' with respect to the price of input ' $\mathrm{j}$ '. Kang and Brown (op. cit.) cite the result from Morishima which relates the full elasticities of substitution to the Allen elasticities as follows:

$$
F_{i j}=s_{j}\left(A_{i j}-A_{j j}\right)=E_{i j}-E_{j j}
$$

$E_{i j}$ is the simple unweighted cross price elasticity of demand for input ' $\mathrm{i}$ ' - it gives the proportional change in the use of input ' $i$ ' for a proportional change in the price of input ' $\mathrm{j}$ '. Given that in almost all conditions the own price elasticity $\left(E_{j j}\right)$ is negative, the full elasticity of substitution will be greater than the corresponding direct price elasticity. The relationship between the Allen and the Full elasticity is less clear but, as we will see below, the latter are typically smaller than the former.

In the simple case of two inputs, we note that the full elasticity of substitution cannot be negative. A negative elasticity of substitution is economically nonsensical - it implies that a decline in the availability of one input can be 'made up' by a decline in the availability of other factors. With more than two inputs it is theoretically possible for this elasticity to be negative but such a case is highly unlikely. It would require the cross price elasticity between two inputs to be negative (indicating they are complements) and to be greater in absolute value than the own price elasticity. Taking capital and natural resource inputs as an example, a negative full elasticity would imply that a one percent increase in the price of the natural resource would reduce inputs of that natural resources by a smaller percent than it decreased the inputs of capital. Note also that by the relation defining $F_{i j}$, the full price elasticity between ' $\mathrm{i}$ ' and ' $\mathrm{j}$ ' is not the same as that between 'j' and 'i' - i.e. $F_{i j} \neq F_{j i}$.

Estimates of the elasticities of substitution are either reported as Allen elasticities or Full elasticities but rarely both. Kang and Brown (op. cit.) have calculated the Full elasticities for some studies where the Allen elasticities are reported. Table 1 gives what estimates are available and indicates which elasticity has been reported.

Previous studies demonstrate Full elasticities that are considerably lower than the Allen elasticities. Moreover, they are almost all positive and less than one. The one exception is the Hudson and Jorgensen (1974) study which suggests that the capital-energy elasticity could be negative. As that study estimates the own price elasticity for energy to be positive, we can probably discount it. 
The other result that has attracted a lot of attention is the difference between those studies that find capital and energy as complements (Allen elasticity is negative) and those that find the two factors as substitutes (Allen elasticity is positive). The differences between these studies have been attributed to a number of factors: use of time series versus cross-section data (Griffin, 1981), response of output to changes in relative prices (Solow, 1987), and different methods of aggregating capital (Garofalo and Malhotra, 1988).

We also note that there is little information in existing studies on the substitutability between natural resources and other inputs. The Parks (1971) study looks at different inputs used in manufacturing, including materials from the agricultural sector, capital and labor. In terms of Allen elasticity, the author finds a complementarity between capital and agricultural inputs, and a substitutability between agricultural inputs and labor. We could not recover the full elasticity but it is likely to be low. The Moroney and Trapani (1981) study finds substitutability between the inputs, labor and exhaustible mineral resources, in mineral-intensive production processes. The two studies are not comparable; nor do they really throw much light on the substitutability issues we are discussing here.

More recent studies have focused on the substitution between energy and another input, such as labor or capital, using the same definition of elasticity that we employ. Manne and Richels (1992) and Chang (1994) estimated the substitution possibilities between the 'capital and labor nest' and energy to be about 0.4; while Kemfert (1998) estimated the same to be about 0.5. On the other hand, Prywes (1986) found the substitution elasticity between the 'capital and energy nest' and labor to be less than 0.5. These studies use the variables capital, labor and energy as relating to stock of fixed assets, skilled and unskilled labor, and final energy consumption, respectively.

\section{Estimation of Nested CES production function}

\section{A. The Nested CES production function and variables}

The estimation carried out here uses national level data on Gross National Income (GNI) or economic output and sees the extent to which variations in GNI across countries at any point in time can be explained in terms of the national availability of produced capital, human resources and natural resources (energy and land resources). A Cobb-Douglas production function of the form shown above is not appropriate for this estimation because it restricts the elasticity between factors to be one. In fact, one of our objectives is to estimate the elasticity of substitution between factors or groups of factors. A form that holds the elasticity constant but allows it to take values different from one is the 'constant elasticity of substitution' (CES) production function. In particular, this paper uses a nested CES production function. For example, a two level nested CES with three inputs takes the form: ${ }^{4}$

$$
X=F\left[X_{A B}(A, B), C\right]
$$

\footnotetext{
${ }^{4}$ This model makes the further assumption of 'homothetic weak separability' for groups of inputs. Homothetic weak separability means that the marginal rate of substitution between inputs in a certain group is independent of output and of the level of inputs outside that group (Chiang, 1984)
} 
where $X$ is the gross output; $A, B$ and $C$ are inputs; and $X_{A B}$ represents the 'joint contribution' of $A$ and $B$ to production. The first level of the estimation involves $A$ and $B$; while the second level models the production of output by $X_{A B}$ and $C$. A special feature of the nested CES function is that the elasticity of substitution between the first level inputs $A$ and $B$ can be different from the elasticity of substitution between the second level inputs $\mathrm{X}_{\mathrm{AB}}$ and $\mathrm{C}$. In other words, by placing natural resources and other inputs in different levels of the function, we effectively allow for different levels of substitutability. So, for example, natural assets may be critical (low substitutability) while other inputs are allowed to be more substitutable among themselves.

In this paper we use related variables to estimate aggregate national level production functions. The variables used are ${ }^{5}$ :

a. Produced capital $(K)$ is an aggregate of equipments, buildings and urban land;

b. Human capital $(H)$ has two alternative measures: human capital, which relates educational attainment with labor productivity (HE); or intangible capital residual (HR), which is obtained as the difference between a country's total wealth and the sum of produced and natural assets. Part of the intangible capital residual captures human capital in the form of raw labor and stock of skills. For further discussion of this variable and its rationale see World Bank (2005a; particularly, Chapter 3 and Chapter 10);

c. Production and net imports of non-renewable energy resources $(E)$ includes oil, natural gas, hard coal and lignite ${ }^{6}$.

d. Land resources $(L)$, which refer to the aggregated value of crop land, pasture land and protected areas. Land is valued in terms of the present value of the income it generates rather than its market value.

The gross national income (GNI) and all inputs mentioned above are measured in per capita values at 2000 prices and are taken at the national level for 208 countries. GNI data are obtained from the World Development Indicators (World Bank, 2005). HE is derived based on the work by Barro and Lee (2000); while the remaining variables, K, HR, E and L are the components of wealth as described in World Bank, 2005a (Chapter 3).

The relationships of the production inputs to income are expressed in nested CES production functions described in the Annex. Three different nested CES approaches are examined - (a) one-level function, with two inputs; (b) two-level function, with three inputs; and (c) three-level function with four inputs. The combinations of the variables in the different CES approaches were varied to further investigate any possible differences among substitution elasticities for pairs of inputs.

The production function approach taken so far neglects an important set of factors that influence differences in national income. These relate to the efficiency with which productive

\footnotetext{
${ }^{5}$ Per capita dollar values at nominal 2000 prices.

${ }^{6}$ For energy it would be inappropriate to take the stock value of the asset, as what is relevant for production is the flow of energy available to the economy. This is given by production plus net imports. With the other assets (K, $\mathrm{H}$ and L) it is also the flow that matters but it is more reasonable to assume that the flow is proportional to the stock. We do note, however, in the conclusions that even this assumption needs to be changed in future work.
} 
assets are utilized and combined and include both institutional as well as economic factors. In this study, we consider the following institutional indicators, which capture the efficiency with which production can take place; as well as economic indicators, which also capture the efficiency of economic organization:

a. institutional development indicators - indices on: voice and accountability (VA); political instability and violence (PIV); government effectiveness (GE); regulatory burden (RB); rule of law (RL) and control of corruption (CC). An increase in a given index measures an improvement in the relevant indicator. Hence, they are expected to have a positive impact on income and possibly growth. These indicators were estimated by Kaufmann, et al, 2005. ${ }^{7}$

b. economic indicators - trade openness (TOPEN) is calculated as the ratio of exports and imports to GDP (World Bank, 2005b); and the country's domestic credit to the private sector as proportion of GDP (PCREDIT), which represents private sector investments (Beck, et al., 1999) ${ }^{8}$.

Two methods of incorporating the impact of these institutional and economic indicators were investigated. The first method involved the derivation of residuals from the regression of a nested CES production function. The residuals are the part of income not explained by the wealth components - physical capital, human capital, land resources and energy resources, and are regressed on the identified institutional and economic indicators. By using this method, however, a statistically significant correlation between the residuals and any indicator would imply that relevant variables have been omitted in the estimation of the nested CES production function. Thus, the estimated coefficients of the nested CES production function earlier derived will be biased and inefficient (Greene, 2000). Hence, another method is considered to be more appropriate. The influences of the institutional and economic indicators on income will be incorporated into the efficiency parameter of the production function, $A$ (see Annex).

Depending on the available data for the variables of the nested CES production function, the number of countries drops in the range of 67 to 93 countries. For a given nested CES approach, the reduction is caused by considering only those countries that have non-missing observations for their corresponding dependent and explanatory variables (i.e., complete case method). ${ }^{9}$

\footnotetext{
${ }^{7}$ Data can be obtained from the website: $h t t p: / / w w w . w o r l d b a n k . o r g / w b i / g o v e r n a n c e / p u b s / g o v m a t t e r s 4 . h t m l$.

${ }^{8}$ Hnatkovska and Loayza (2004) use openness and credit as a measure of financial depth, which they find to have a positive impact on growth. Data for this indicator can be obtained from the following website: http://www.worldbank.org/research/projects/finstructure/database.htm.

${ }^{9}$ An "imputation method" was tried to fill the missing values for some of the countries to keep all 208 countries in the estimation. Most of the results, however, were not found to be reasonable. For example, the imputed value of physical capital for a low income country turned out to be too high compared to the average value of physical capital of its income group. Hence, the imputation method was not used since it poses more problems in the estimates than using the complete case method.
} 


\section{B. Regression results}

The nested CES production functions are estimated using a non-linear estimation method. ${ }^{10}$ The sample size in each CES approach differs because countries with missing observations in any of the variables had to be dropped. Table 2 shows the estimated substitution elasticities corresponding to the case where human capital is part of the measured intangible capital residual (HR). All the statistically significant substitution elasticity estimates have a positive sign, which is encouraging. The lowest is that between $\mathrm{K}$ and $\mathrm{E}$ at 0.37 in the threelevel production function. It is also interesting to note that most of the significant elasticities of substitution are close to one.

A second round of regressions was carried out using the other measure of human capital that is related to schooling and labor productivity, HE. Table 3 shows the statistically significant elasticities of substitution, which also have a positive sign. A substitution elasticity approximately equal to 1 is likewise found for most of the nested functions.

The results provide some interesting findings. First and foremost, there is no sign that the elasticity of substitution between the natural resource (land) and other inputs is particularly low. Wherever land emerges as a significant input, it has an elasticity of substitution approximately equal to or greater than one. Second, by and large, the HE variable performs better in the estimation equations than the HR variable. Third, the best determined forms, with all parameters significant are those using $\mathrm{HE}$, involving four factors and containing the following combinations: (a) K, HE and L are nested together and then combine with E; or (b) K, HE and E are nested together and then combine with L. ${ }^{11}$ It is hard to distinguish between these two versions and so they are both used in the further analysis reported below.

From the nested CES production function estimations, the elasticity estimates of the institutional and economic indicators can be derived. Table 4 and Table 5 show the results for the four-factor production functions: [(K,HE,L)/E] and [(K,E,HE)/L] of Table 3, respectively. In both Tables, the variables on trade openness and private sector investment are found to be statistically significant. The elasticity estimates of these two variables are not very different from each other. The results imply that for every percent increase in trade openness, gross national income per capita increases by approximately 0.5 percent. None of the institutional indicators, on the other hand, has a statistically significant elasticity estimate. ${ }^{12}$

\footnotetext{
${ }^{10}$ See Annex for more details.

11 "Inputs nested together" refers to the joint contribution of these inputs to the production of output, as indicated in Section III of this paper.

${ }^{12}$ In the regression where the 'residuals' are expressed as a function of the institutional variables, we did find significant values for a few institutional variables, especially the rule of law, which was encouraging as that variable also emerges as important in other evaluations of inter-country differences in the World Bank (2005a) study. Unfortunately, the result did not hold when the more appropriate method was used.
} 


\section{Simulation}

The predicted value of the dependent variable can be calculated by using the estimated coefficient estimates of the production function and the mean values of the explanatory variables. Through this method, we try to predict what will happen to the economic output (per capita GNI or GNIPC) if there is significant natural resource depletion. The natural resource considered in this exercise is "land resources (L)" and the four-factor nested CES production functions used are: $[(\mathrm{K}, \mathrm{HE}, \mathrm{L}) / \mathrm{E}]$ and $[(\mathrm{K}, \mathrm{E}, \mathrm{HE}) / \mathrm{L}]$ of Table 3 . Table 6 presents the predicted average GNIPC as well as the change in GNIPC given a reduction in the amount of land resources, ceteris paribus. Based on the production function $[(\mathrm{K}, \mathrm{HE}, \mathrm{L}) / \mathrm{E}]$, economic output is reduced by 50 percent when the amount of $\mathrm{L}$ declines by about 92 percent, while holding other variables constant. For the production function [(K,E,HE)/L], on the other hand, it takes a reduction in the amount of L by about the same percentage, ceteris paribus, to halve the economic output relative to the baseline.

\section{Conclusions}

In this paper we looked at the potential for substituting between different inputs in the generation of GNI. Among these are land resources, one of the most important natural resources. The estimation of a well-known production function form, which allows the elasticities of substitution to be different from one, was carried out. The resulting elasticities involving land resources (between L and other inputs such as physical capital, human capital and energy resources) were generally around one or greater, which implies a fairly high degree of substitutability. Moreover, it validates the use of a 'Hartwick Rule' of saving the rents from the exploitation of natural resources if we are to follow a maximum constant sustainable consumption path.

There are, of course, many caveats to this result. Land resources, as measured here include crop land, pasture land and protected areas. Each has been valued in terms of the present value of the flow of income that it generates. Such flows, however, under-represent the importance of protected areas for example, which provide significant non-monetary services, including ecosystem maintenance services that are not included. Further work is needed to include these values, and if this were done, and if the GNI measure were adjusted to allow for these flows of 'income', the resulting estimates of substitution elasticities might well change. We intend to continue to work along these lines and to improve the estimates made here.

Another shortcoming of the method applied here is the limited number of factors included in the original estimation. Generating national income depends not on the stock of assets but the amounts of the stocks that are used in production and the way in which they are used. For physical and human capital and land, we assume the rate of use is proportional to the stock. That assumption should be improved on, to allow for different utilization rates.

The treatment of institutional factors can also be improved. In this version, they are assumed to affect the overall efficiency of production rather than the efficiency of specific inputs, such as capital and labor. A modified estimation equation in which $\mathrm{K}, \mathrm{L}$ and HE were 
differently affected by different institutional factors would probably find greater significance for these factors than we have.

Finally, the paper also examined how the institutional and economic indicators will affect the generation of GNI. Estimation results show that income generation is significantly influenced by changes in trade openness and private sector investment. The institutional indicators, however, have no statistically significant impact on income generation. 
Table 1: Estimates of elasticities of substitution in previous studies

\begin{tabular}{|l|c|c|l|}
\hline \multirow{2}{*}{ Inputs } & \multicolumn{2}{|c|}{ Estimates } & \multirow{2}{*}{ Study } \\
\cline { 2 - 3 } & Allen Elasticity & Full Elasticity & \\
\hline Capital and natural & -0.82 & - & Parks (1971) \\
resource inputs & $(0.47 ; 1.08)^{\mathrm{a}}$ & - & Moroney and Trapani (1981) \\
\hline Labor and natural & 0.90 & - & Parks (1971) \\
resource inputs & $(0.63 \text { to } 1.33)^{\mathrm{b}}$ & - & Moroney and Trapani (1981) \\
\hline Capital and Labor & 0.12 & - & Parks (1971) \\
& 1.09 & $(0.56: 0.74)^{*}$ & Hudson and Jorgenson (1974) \\
& 1.01 & - & Brendt and Wood (1979) \\
& $(.06: 0.39)$ & $(0.17: 0.19)^{*}$ & Griffin and Gregory (1976) \\
& $0.60: 0.95)$ & - & Moroney and Trapani (1981) \\
& 0.88 & - & Prywes (1986) \\
\hline Capital and Energy & -1.39 & $(-0.09: 0.24)^{*}$ & Kemfert (1998) \\
& -3.22 & $0.26^{* *}$ & Budson and Jorgenson (1974) \\
& $1.03: 1.07$ & $(0.33: 0.92)^{*}$ & Griffin and Gregory (1976) \\
& -1.35 & - & Prywes (1986) \\
& 2.17 & $0.87^{* *}$ & Chang (1994) \\
& - & $0.65^{* *}$ & Kemfert (1998) \\
\hline Labor and Energy & 2.16 & - & Hudson and Jorgenson (1974) \\
& 0.65 & - & Brendt and Wood (1975) \\
& $(0.84: 0.87)$ & - & Griffin and Gregory (1976) \\
& 0.88 & - & Prywes (1986) \\
& 0.35 & - & Chang (1994) \\
& & $0.42^{* *}$ & Kemfert (1998) \\
\hline Labor and Capital & - & $0.40^{* *}$ & Manne and Richels (1992) \\
'nest' and Energy & - & $0.42^{* *}$ & Chang (1994) \\
& & $0.50^{* *}$ & Kemfert (1998) \\
\hline
\end{tabular}

The figures are rounded off to the nearest hundredth.

Unless stated otherwise, the elasticities above are calculated for the aggregate of the industry.

Energy - the variable refers to total energy consumption

${ }^{a}$ The given Allen elasticities are statistically significant only for two industries: primary aluminum and blast furnaces/basic steel, respectively.

${ }^{\mathrm{b}}$ A range is given to cover the estimated elasticities for 4 of the 6 industries studied: primary aluminum, blast furnaces/basic steel, storage batteries and hydraulic cement.

$(*) \quad$ The full elasticity was calculated by Kang and Brown (1981)

$(* *)$ The full elasticity was calculated by the authors

Study focus and estimation method:

Parks (1971):

Moroney and Trapani (1981):

Hudson and Jorgenson (1974):

Berndt and Wood (1979):

Griffin and Gregory (1976):

Prywes (1986):

Manne and Richels (1992):

Chang (1994):

Kemfert (1998):
Swedish manufacturing industry; Generalized Leontief Function

Mineral-intensive manufacturing industries; Translog cost model

U.S. manufacturing sector; Translog cost function

U.S. manufacturing sector; Translog cost function

U.S. and U.K. manufacturing sectors, respectively; Translog cost function

Manufacturing sector; Nested CES estimation.

Manufacturing sector; Nested CES

Taiwan manufacturing industry (aggregate); Nested CES and Allen elasticities of substitution

German manufacturing industry (aggregate); Nested CES 
Table 2: Substitution elasticities $\left(\hat{\sigma}_{i}\right)$, using intangible capital residual (HR)

\begin{tabular}{|c|c|c|c|c|c|c|}
\hline & \multirow[t]{2}{*}{ Inputs } & \multicolumn{2}{|c|}{ Substitution elasticity } & \multirow[t]{2}{*}{ R-squared } & \multirow{2}{*}{$\begin{array}{l}\text { Adj. R- } \\
\text { squared }\end{array}$} & \multirow{2}{*}{$\begin{array}{c}\text { Sample } \\
\text { size }\end{array}$} \\
\hline & & $\hat{\sigma}_{i}$ & $\begin{array}{l}\text { Standard } \\
\text { error }\end{array}$ & & & \\
\hline \multicolumn{7}{|c|}{ A. Two factors (One level CES production function) } \\
\hline (1) & $\mathrm{K} / \mathrm{HR}$ & $1.00^{*}$ & $3.88 \mathrm{E}-10$ & 0.9216 & 0.9131 & 93 \\
\hline (2) & $\mathrm{K} / \mathrm{E}$ & -0.48 & 2.02 & 0.9958 & 0.9951 & 78 \\
\hline \multicolumn{7}{|c|}{ B. Three factors (Two level CES production function) } \\
\hline \multirow[t]{3}{*}{ (1) } & \multicolumn{3}{|c|}{$(\mathrm{K}, \mathrm{HR}) / \mathrm{L}$} & 0.9375 & 0.9290 & 93 \\
\hline & $>\mathrm{K} / \mathrm{HR}$ & 6.79 & 13.92 & & & \\
\hline & $>(\mathrm{K}, \mathrm{HR}) / \mathrm{L}^{1}$ & $1.00 *$ & $4.33 \mathrm{E}-10$ & & & \\
\hline \multirow[t]{3}{*}{ (2) } & \multicolumn{3}{|l|}{$(\mathrm{K}, \mathrm{HR}) / \mathrm{E}$} & 0.9089 & 0.8916 & 70 \\
\hline & $>\mathrm{K} / \mathrm{HR}$ & -0.78 & 1.31 & & & \\
\hline & $>(\mathrm{K}, \mathrm{HR}) / \mathrm{E}^{1}$ & $1.00^{*}$ & $5.37 \mathrm{E}-10$ & & & \\
\hline \multirow[t]{3}{*}{ (3) } & \multicolumn{3}{|l|}{$(\mathrm{K}, \mathrm{E}) / \mathrm{HR}$} & 0.87667 & 0.8533 & 70 \\
\hline & $>\mathrm{K} / \mathrm{E}$ & 0.65 & 0.69 & & & \\
\hline & $>(\mathrm{K}, \mathrm{E}) / \mathrm{HR}^{1}$ & $1.00^{*}$ & 3.96E-09 & & & \\
\hline \multicolumn{7}{|c|}{ C. Four factors (Three level CES production function) } \\
\hline \multirow[t]{4}{*}{ (1) } & \multicolumn{3}{|c|}{$(\mathrm{K}, \mathrm{HR}, \mathrm{L}) / \mathrm{E}$} & 0.3435 & 0.1911 & 70 \\
\hline & $>\mathrm{K} / \mathrm{HR}$ & -0.90 & 0.70 & & & \\
\hline & $>(\mathrm{K}, \mathrm{HR}) / \mathrm{L}^{1}$ & $0.97 *$ & 0.01 & & & \\
\hline & $>(\mathrm{K}, \mathrm{HR}, \mathrm{L}) / \mathrm{E}^{2}$ & $1.00 *$ & $5.46 \mathrm{E}-12$ & & & \\
\hline \multirow[t]{4}{*}{ (2) } & \multicolumn{3}{|l|}{$(\mathrm{K}, \mathrm{HR}, \mathrm{E}) / \mathrm{L}$} & 0.9958 & 0.9951 & 78 \\
\hline & $>\mathrm{K} / \mathrm{HR}$ & -0.13 & 0.17 & & & \\
\hline & $>(\mathrm{K}, \mathrm{HR}) / \mathrm{E}^{1}$ & $0.93^{*}$ & 0.18 & & & \\
\hline & $>(\mathrm{K}, \mathrm{HR}, \mathrm{E}) / \mathrm{L}^{2}$ & $1.00^{*}$ & $6.52 \mathrm{E}-09$ & & & \\
\hline \multirow[t]{4}{*}{ (3) } & \multicolumn{3}{|l|}{$(\mathrm{K}, \mathrm{E}, \mathrm{HR}) / \mathrm{L}$} & 0.9350 & 0.9200 & 70 \\
\hline & $>\mathrm{K} / \mathrm{E}$ & $0.37 *$ & 0.20 & & & \\
\hline & $>(\mathrm{K}, \mathrm{E}) / \mathrm{HR}^{1}$ & -0.64 & 0.55 & & & \\
\hline & $>(\mathrm{K}, \mathrm{E}, \mathrm{HR}) / \mathrm{L}^{2}$ & $1.00^{*}$ & $1.27 \mathrm{E}-09$ & & & \\
\hline
\end{tabular}

Legend: K - physical capital; HR - intangible capital residual (captures raw labor and stock of skills); L - land resources; E - energy resources

Notes: Inputs in parenthesis imply that they are nested.

${ }^{1}$ two inputs in a nested function

${ }^{2}$ three inputs in a nested function

(*) denotes statistical significance at $5 \%$ level

The substitution elasticities and their corresponding standard errors are rounded off to the nearest hundredth. 
Table 3: Substitution elasticities $\left(\hat{\sigma}_{i}\right)$, using human capital related to schooling (HE)

\begin{tabular}{|c|c|c|c|c|c|c|}
\hline & \multirow[t]{2}{*}{ Inputs } & \multicolumn{2}{|c|}{ Substitution elasticity } & \multirow[t]{2}{*}{ R-squared } & \multirow{2}{*}{$\begin{array}{l}\text { Adj. R- } \\
\text { squared }\end{array}$} & \multirow{2}{*}{$\begin{array}{c}\text { Sample } \\
\text { size }\end{array}$} \\
\hline & & $\hat{\sigma}_{i}$ & $\begin{array}{l}\text { Standard } \\
\text { error }\end{array}$ & & & \\
\hline \multicolumn{7}{|c|}{ A. Two factors (One level CES production function) } \\
\hline (1) & $\mathrm{K} / \mathrm{HE}$ & $1.00 *$ & $2.50 \mathrm{E}-08$ & 0.9061 & 0.8942 & 81 \\
\hline \multicolumn{7}{|c|}{ B. Three factors (Two level CES production function) } \\
\hline (1) & \multicolumn{3}{|c|}{$(\mathrm{K}, \mathrm{HE}) / \mathrm{L}$} & 0.9203 & 0.9076 & 81 \\
\hline & $>\mathrm{K} / \mathrm{HE}$ & $1.01 *$ & 0.01 & & & \\
\hline & $>(\mathrm{K}, \mathrm{HE}) / \mathrm{L}^{1}$ & $1.00 *$ & $2.23 \mathrm{E}-10$ & & & \\
\hline$(2)$ & \multicolumn{3}{|l|}{$(\mathrm{K}, \mathrm{HE}) / \mathrm{E}$} & 0.8952 & 0.8742 & 67 \\
\hline & $>\mathrm{K} / \mathrm{HE}$ & $1.65^{*}$ & 0.12 & & & \\
\hline & $>(\mathrm{K}, \mathrm{HE}) / \mathrm{E}^{1}$ & $1.00 *$ & $6.76 \mathrm{E}-11$ & & & \\
\hline (3) & \multicolumn{3}{|l|}{$(\mathrm{K}, \mathrm{E}) / \mathrm{HE}$} & 0.7674 & 0.7209 & 67 \\
\hline & $>\mathrm{K} / \mathrm{E}$ & 0.17 & 0.19 & & & \\
\hline & $>(\mathrm{K}, \mathrm{E}) / \mathrm{HE}^{1}$ & $1.00 *$ & 8.22E-08 & & & \\
\hline \multicolumn{7}{|c|}{ C. Four factors (Three level CES production function) } \\
\hline (1) & \multicolumn{3}{|c|}{$(\mathrm{K}, \mathrm{HE}, \mathrm{L}) / \mathrm{E}$} & 0.9037 & 0.8081 & 67 \\
\hline & $>\mathrm{K} / \mathrm{HE}$ & $1.78 *$ & 0.11 & & & \\
\hline & $>(\mathrm{K}, \mathrm{HE}) / \mathrm{L}^{1}$ & $1.14^{*}$ & 0.02 & & & \\
\hline & $>(\mathrm{K}, \mathrm{HE}, \mathrm{L}) / \mathrm{E}^{2}$ & $1.00 *$ & $2.52 \mathrm{E}-12$ & & & \\
\hline (2) & \multicolumn{3}{|l|}{$(\mathrm{K}, \mathrm{HE}, \mathrm{E}) / \mathrm{L}$} & 0.9059 & 0.8828 & 67 \\
\hline & $>\mathrm{K} / \mathrm{HE}$ & -8.55 & 12.61 & & & \\
\hline & $>(\mathrm{K}, \mathrm{HE}) / \mathrm{E}^{1}$ & $0.48^{*}$ & 0.17 & & & \\
\hline & $>(\mathrm{K}, \mathrm{HE}, \mathrm{E}) / \mathrm{L}^{2}$ & $1.00 *$ & 4.60E-11 & & & \\
\hline (3) & \multicolumn{3}{|l|}{$(\mathrm{K}, \mathrm{E}, \mathrm{HE}) / \mathrm{L}$} & 0.9062 & 0.8831 & 67 \\
\hline & $>\mathrm{K} / \mathrm{E}$ & $1.57 *$ & 0.37 & & & \\
\hline & $>(\mathrm{K}, \mathrm{E}) / \mathrm{HE}^{1}$ & $0.92 *$ & 0.02 & & & \\
\hline & $>(\mathrm{K}, \mathrm{E}, \mathrm{HE}) / \mathrm{L}^{2}$ & $1.00 *$ & $6.41 \mathrm{E}-11$ & & & \\
\hline
\end{tabular}

Legend: $\mathrm{K}$ - physical capital; $\mathrm{HE}$ - human capital related to educational attainment and labor productivity; $\mathrm{L}$ - land resources; E - energy resources

Notes: Inputs in parenthesis imply that they are nested.

${ }^{1}$ two inputs in a nested function

${ }^{2}$ three inputs in a nested function

(*) denotes statistical significance at $5 \%$ level; $(* *)$ at $10 \%$ level

The substitution elasticities and their corresponding standard errors are rounded off to the nearest hundredth. 
Table 4: Elasticity estimates of the economic and institutional indicators using the $[(\mathrm{K}, \mathrm{HE}, \mathrm{L}) / \mathrm{E}]$ production function

\begin{tabular}{|l|c|c|c|}
\hline Variable & Elasticity & Standard error & t-statistic \\
\hline TOPEN & 0.47 & 0.10 & 4.53 \\
\hline PCREDIT & 0.51 & 0.12 & 4.25 \\
\hline VA & 0.01 & 0.04 & 0.28 \\
\hline PIV & -0.01 & 0.02 & -0.28 \\
\hline GE & 0.04 & 0.10 & 0.40 \\
\hline RB & 0.03 & 0.07 & 0.39 \\
\hline RL & -0.07 & 0.10 & -0.73 \\
\hline CC & 0.01 & 0.09 & 0.17 \\
\hline
\end{tabular}

Legends: TOPEN-trade openness; PCREDIT- variable for private sector investment; VA - voice and accountability; PIV- political instability and violence; GE - government effectiveness; RB - regulatory burden; RL - rule of law; and CC - control of corruption.

Table 5: Elasticity estimates of the economic and institutional indicators using the $[(\mathrm{K}, \mathrm{E}, \mathrm{HE}) / \mathrm{L}]$ production function

\begin{tabular}{|l|c|c|c|}
\hline Variable & Elasticity & Standard error & t-statistic \\
\hline TOPEN & 0.50 & 0.09 & 5.27 \\
\hline PCREDIT & 0.51 & 0.11 & 4.83 \\
\hline VA & 0.02 & 0.03 & 0.45 \\
\hline PIV & -0.01 & 0.02 & -0.44 \\
\hline GE & 0.06 & 0.09 & 0.62 \\
\hline RB & 0.03 & 0.07 & 0.37 \\
\hline RL & -0.08 & 0.09 & -0.86 \\
\hline CC & -0.02 & 0.08 & -0.24 \\
\hline
\end{tabular}

Legends: TOPEN-trade openness; PCREDIT- variable for private sector investment; VA - voice and accountability; PIV- political instability and violence; GE - government effectiveness; RB - regulatory burden; RL - rule of law; and CC - control of corruption.

Table 6: Level of Gross National Income per capita given a reduction in the amount of land

\begin{tabular}{|c|c|c|c|c|c|}
\hline \multirow[t]{2}{*}{ Prod. function } & \multirow[t]{2}{*}{ Baseline* } & \multicolumn{4}{|c|}{ Reduction in the amount of land by } \\
\hline & & $20 \%$ & $50 \%$ & $75 \%$ & $92 \%$ \\
\hline$(\mathrm{K}, \mathrm{HE}, \mathrm{L}) / \mathbf{E}$ & $\$ 8,638.10$ & $\$ 8,068.84$ & $\$ 7,019.27$ & $\$ 5,774.25$ & $\$ 4,297.16$ \\
\hline \multicolumn{2}{|c|}{ Difference from baseline ${ }^{* *}$} & $(-7 \%)$ & $(-19 \%)$ & $(-33 \%)$ & $(-50 \%)$ \\
\hline$(\mathrm{K}, \mathrm{E}, \mathrm{HE}) / \mathrm{L}$ & $\$ 9,096.20$ & $\$ 8,540.27$ & $\$ 7,477.97$ & $\$ 6,147.62$ & $\$ 4,455.06$ \\
\hline \multicolumn{2}{|c|}{ Difference from baseline ${ }^{* *}$} & $(-6 \%)$ & $(-18 \%)$ & $(-32 \%)$ & $(-51 \%)$ \\
\hline
\end{tabular}

*Predicted per capita GNI at the mean values of the explanatory variables.

$* *$ Rounded off to the nearest whole number

Sample size of each production function $=67$ 


\section{References}

Anderson, K., 1972. "Optimal Growth When the Stock of Resources is Finite and Depletable.” Journal of Economic Theory, 4(2): 256-67.

Barro R. and J.W. Lee. 2000. "International Data on Educational Attainment: Updates and Implications.” CID Working Paper No. 42. Center for International Development, Harvard University.

Beck, T., Demirgüç-Kunt, A. and Levine, R. 1999. “A New Database on Financial Development and Structure.” World Bank Economic Review, 14(3): 597-605.

Berndt, E. and D. Wood. 1979. "Engineering and Econometric Interpretation of Energy-Capital Complementarity.” American Economic Review, 69: 342-354.

Berndt, E. and B. Field (eds). 1981. Modeling and Measuring Natural Resource Substitution, Cambridge MA: MIT Press.

Chang, K. 1994. “Capital-energy Substitution and the Multi-level CES Production Function.” Energy Economics, 16(1): 22-26.

Chiang, A.C. 1984. Fundamental Methods of Mathematical Economics, $3^{\text {rd }}$ edition. Singapore: McGraw-Hill Book Company.

Garofalo, A.and D. Malhotra. 1988. “Aggregation of Capital and Its Substitution with Energy.” Eastern Economic Journal, 14(3): 251-262.

Greene, W. 2000. Econometric Analysis, $4^{\text {th }}$ edition. Prentice Hall, USA.

Griffin, J. and P. Gregory. 1976. “An Intercountry Translog Model of Energy Substitution Responses.” American Economic Review, 66: 845-857.

Griffin, J. 1981. "Engineering and Econometric Interpretations of Energy-Capital Complementarity: Comment.” American Economic Review, 71(5): 1100-1104.

Hamilton, K. 1995. "Sustainable Development, the Hartwick Rule and Optimal Growth.” Environmental and Resource Economics, 5: 393411.

Hnatkovska, V. and Loayza, N. 2004. “Volatility and Growth,” in Managing Volatility and Crises: A Practitioner's Guide, eds B. Pinto et al. The World Bank, Washington, D.C.

Hudson, E. and D. Jorgenson. 1974. "U.S. Energy Policy and Economic Growth, 1975-2000.” Bell Journal of Economics and Management Science, 5: 461-514. 
Kang, H. and Brown, G.M. "Partial and Full Elasticities of Substitution and the Energy-Capital Complementary Controversy”, Chapter 5 in Berndt, E. and B. Field (eds). 1981. Modeling and Measuring Natural Resource Substitution, Cambridge MA: MIT Press.

Kaufmann, D., A. Kraay and M. Mastruzzi. 2005. “Governance Matters IV: Governance Indicators for 1996-2004”, World Bank Institute Working Paper. The World Bank, Washington, D.C.

Kemfert, C. and H. Welsch. 2000. "Energy-capital-labor substitution and the economic effects of CO2 abatement: Evidence for Germany.” Journal of Policy Modeling, 22(6): 641-660.

Kemfert, C. 1998. "Estimated production elasticities of a nested CES production function approach for Germany”. Energy Economics, 20: 249-264.

Manne, A. and R. Richels. 1992. Buying Greenhouse Insurance: The Economic Costs of $\mathrm{CO}_{2}$ Emission Limits. U.S.A.:MIT Press.

Mitra, T. 1978. “Efficient Growth with Exhaustible Resources in a Neoclassical Model”, Journal of Economic Theory, 17(1): 114-29.

Moroney, J. and J. Trapani. 1981. "Factor Demand and Substitution in Mineral-intensive Industries.” Bell Journal of Economics, 12(1): 272-284.

Parks, R. 1971. "Price Responsiveness of Factor Utilization in Swedish Manufacturing, 18701950.” Review of Economics and Statistics, 53(2): 129-139.

Prywes, M. 1986. “A Nested CES Approach to Capital-Energy Substitution.” Energy Economics, 8: 22-28.

Solow, J. 1987. “The Capital-Energy Complementarity Debate Revisited.” American Economic Review, 77(4): 605-614.

Stiglitz, J.E. 1974a. "Growth with Exhaustible Natural Resources: Efficient and Optimal Growth Paths.” Review of Economic Studies, pp. 123-37.

Stiglitz, J.E. 1974b. "Growth with Exhaustible Natural Resources: The Competitive Economy." Review of Economic Studies, pp. 139-52

Wagner, G. 2004. “Environmental Macroeconomics Bibliography.” Available at: http://www.gwagner.net/work/environmental_macroeconomics.html

World Bank 2005a. Where is the Wealth of Nations? U.S.A.: The World Bank.

World Bank. 2005b. World Development Indicators. U.S.A.: The World Bank. 


\section{Annex}

\section{Three different CES approaches}

1. A one-level nested CES is a traditional CES production function with two inputs and written as:

(i) physical capital $(K)$ and human capital $(H)$

$$
Y=A\left(a K^{-\beta}+b H^{-\beta}\right)^{-1 / \beta}
$$

(ii) physical capital $(K)$ and energy resources $(E)$

$$
Y=A\left(a K^{-\beta}+b E^{-\beta}\right)^{-1 / \beta}
$$

where $Y$ is the per capita gross national income. $A$ is an efficiency parameter. $a$ and $b$ are distribution parameters that lie between zero and one; and $\beta$ represents the substitution parameter. The substitution elasticity $(\sigma)$ is calculated as: $\sigma=(1 / 1+\beta)$. Values of $\beta$ must be greater than -1 (a value less than -1 is economically nonsensical, although it has been observed in a number of studies - see for example, Prywes, 1986). If $\beta>-1$ the substitution elasticity must of course be positive.

$\boldsymbol{A}$, the efficiency parameter, is assumed to be a function of the economic (TOPEN and PCREDIT) and institutional indicators described in the text. Two functional forms of $A$ have been tried:

(a) $A=e^{\lambda_{1} T O P E N+\lambda_{2} P C R E D I T+\lambda_{3} V A+\lambda_{4} P I V+\lambda_{5} G E+\lambda_{6} R B+\lambda_{7} R L+\lambda_{8} C C}$

(b) $A=\lambda_{1} T O P E N+\lambda_{2} P C R E D I T+\lambda_{3} V A+\lambda_{4} P I V+\lambda_{5} G E+\lambda_{6} R B+\lambda_{7} R L+\lambda_{8} C C$

and the second functional form of $A$ was found to be more appropriate.

TOPEN means trade openness; PCREDIT is a variable for private sector investment; VA, voice and accountability; PIV, political instability and violence; GE, government effectiveness; RB, regulatory burden; RL, rule of law; and CC, control of corruption. The scores for each institutional indicator lie between -2.5 and 2.5, with higher scores corresponding to better outcomes.

2. A two-level nested CES production function with three inputs is investigated for three cases:

(i) $K$ and $H$ in the nested function, $X_{K H}$ is a substitute to land resources $(L)$ :

$$
Y_{1}=A_{1}\left[a_{1}\left(b_{1} K^{-\alpha_{1}}+\left(1-b_{1}\right) H^{-\alpha_{1}}\right)^{\beta_{1} / \alpha_{1}}+\left(1-a_{1}\right) L^{-\beta_{1}}\right]^{-1 / \beta_{1}}
$$

(ii) $K$ and $H$ in the nested function, $X_{K H}$ is a substitute to energy resources $(E)$;

$$
Y_{2}=A_{2}\left[a_{2}\left(b_{2} K^{-\alpha_{2}}+\left(1-b_{2}\right) H^{-\alpha_{2}}\right)^{\beta_{2} / \alpha_{2}}+\left(1-a_{2}\right) E^{-\beta_{2}}\right]^{-1 / \beta_{2}}
$$


(iii) $K$ and $E$ in the nested function, $X_{K E}$ is a substitute to human capital $(H)$;

$$
Y_{3}=A_{3}\left[a_{3}\left(b_{3} K^{-\alpha_{3}}+\left(1-b_{3}\right) E^{-\alpha_{3}}\right)^{\beta_{3} / \alpha_{3}}+\left(1-a_{3}\right) H^{-\beta_{3}}\right]^{-1 / \beta_{3}}
$$

where $\alpha_{i}$ and $\beta_{i}$ are substitution parameters.

3. A three-level nested CES production function with four inputs is studied for these three cases:

(i) $K, H$ and $L$ in the nested function, and $E$ as a substitute to $X_{K H L}$ :

$$
Y_{4}=A_{4}\left\{a_{4}\left[b_{4}\left(c_{4} K^{-\alpha_{4}}+\left(1-c_{4}\right) H^{-\alpha_{4}}\right)^{\rho_{4} / \alpha_{4}}+\left(1-b_{4}\right) L^{-\rho_{4}}\right]^{\beta_{4} / \rho_{4}}+\left(1-a_{4}\right) E^{-\beta_{4}}\right\}^{-1 / \beta_{4}}
$$

(ii) $P, H$ and $E$ in the nested function, and $L$ as a substitute to $X_{K H E}$;

$$
Y_{5}=A_{5}\left\{a_{5}\left[b_{5}\left(c_{5} K^{-\alpha_{5}}+\left(1-c_{5}\right) H^{-\alpha_{5}}\right)^{\rho_{5} / \alpha_{5}}+\left(1-b_{5}\right) E^{-\rho_{5}}\right]^{\beta_{5} / \rho_{5}}+\left(1-a_{5}\right) L^{-\beta_{5}}\right\}^{-1 / \beta_{5}}
$$

(iii) $K, E$ and $H$ in the nested function, and $L$ as a substitute to $X_{K E H}$.

$$
Y_{6}=A_{6}\left\{a_{6}\left[b_{6}\left(c_{6} K^{-\alpha_{6}}+\left(1-c_{6}\right) E^{-\alpha_{6}}\right)^{\rho_{6} / \alpha_{6}}+\left(1-b_{6}\right) H^{-\rho_{6}}\right]^{\beta_{6} / \rho_{6}}+\left(1-a_{6}\right) L_{6}^{-\beta_{6}}\right\}^{-1 / \beta_{6}}
$$

\begin{tabular}{|c|c|}
\hline$\sigma_{\alpha_{i}}=1 / 1+\alpha_{i}$ & $\begin{array}{l}\text { Gives the elasticity of substitution between } K \text { and } H \text { when ' } i \text { ' }=1,2,4,5 \\
\text { Gives the elasticity of substitution between } K \text { and } E \text { when ' } i \text { ' }=1,6\end{array}$ \\
\hline$\sigma_{\rho_{i}}=1 / 1+\rho_{i}$ & $\begin{array}{l}\text { Gives the elasticity of substitution between } \mathrm{K} / \mathrm{H} \text { and } \mathrm{L} \text { when ' } \mathrm{i} \text { ' }=4 \\
\text { Gives the elasticity of substitution between } \mathrm{K} / \mathrm{H} \text { and } \mathrm{E} \text { when ' } \mathrm{i} \text { ' }=5 \\
\text { Gives the elasticity of substitution between } \mathrm{K} / \mathrm{E} \text { and } \mathrm{H} \text { when ' } \mathrm{i} \text { ' }=6\end{array}$ \\
\hline$\sigma_{\beta_{i}}=1 / 1+\beta_{i}$ & $\begin{array}{l}\text { Gives the elasticity of substitution between } \mathrm{K} / \mathrm{H} \text { and } \mathrm{L} \text { when ' } \mathrm{i} \text { ' }=1 \\
\text { Gives the elasticity of substitution between } \mathrm{K} / \mathrm{H} \text { and } \mathrm{E} \text { when ' } \mathrm{i} \text { ' }=2 \\
\text { Gives the elasticity of substitution between } \mathrm{K} / \mathrm{E} \text { and } \mathrm{H} \text { when ' } \mathrm{i} \text { ' }=3 \\
\text { Gives the elasticity of substitution between } \mathrm{K} / \mathrm{H} / \mathrm{L} \text { and } \mathrm{E} \text { when ' } \mathrm{i} \text { ' }=4 \\
\text { Gives the elasticity of substitution between } \mathrm{K} / \mathrm{H} / \mathrm{E} \text { and } \mathrm{L} \text { when ' } \mathrm{i} \text { ' }=5 \\
\text { Gives the elasticity of substitution between } \mathrm{K} / \mathrm{E} / \mathrm{H} \text { and } \mathrm{L} \text { when ' } \mathrm{i} \text { ' }=6\end{array}$ \\
\hline
\end{tabular}

where $\alpha_{i}, \rho_{i}, \beta_{i}$ are substitution parameters; and $0<a_{i}, b_{i}, c_{i}<1$.

The substitution elasticities for these CES Approaches can be described as follows:

The nested CES production functions are estimated using the non-linear estimation method via the STATA program. The non-linear estimation program uses an iterative procedure to find the parameter values in the relationship that cause the sum of squared residuals (SSR) to be minimized. It starts with approximate guesses of the parameter values (also called, "starting values"), and computes the residuals and then the SSR. The starting values are a combination of 
arbitrary values and coefficient estimates of a nested CES production function. For example, the starting values of Equation (A.1) are arbitrary. A set of numbers is tried until convergence is achieved. On the other hand, the starting values of Equation (A.3) are based on the coefficient estimates of Equation (A.1). Next, it changes one of the parameter values slightly, computes again the residuals to see if the SSR becomes smaller or larger. The iteration process goes on until there is convergence - until it finds parameter values that, when changed slightly in any direction, causes the SSR to rise. Hence, these parameter values are the least squares estimate in the nonlinear context. 